\title{
La lección de Parménides y el trabajo social. Sobre la rentabilidad intelectual de los dominios menores*
}

\author{
José L. MORENO \\ Universidad de Cádiz \\ joseluis.moreno@uca.es
}

Recibido: 05.12 .2008

Aceptado: 26.05 .2009

\begin{abstract}
«A pesar de lo que digan los detractores de Mayo, aquél fue un hermoso momento, en que uno podía hablar con cualquiera, anónimo, impersonal, un hombre entre otros hombres y saludarse sin más explicación que la de ser uno más» (Blanchot, 1988: 7).

«Los intelectuales flotantes tienen una relación con el espíritu científico que es, al menos tan heterónoma, como la que tienen los «intelectuales orgánicos» jerarquizados en un Estado, en una Iglesia o un Partido. Seguidismo o necesidad de admirar, pereza o activismo, diletantismo o snobismo contribuyen, en proporciones variables según los casos, a transformar los intelectuales sin obra en auditores o lectores indiferentes a la estructura lógica de las argumentaciones científicas. Ya sea, en los adversarios de humor, para rechazar mejor levantando las hombros sin exponerse al riesgo de un debate técnico o, en los discípulos fascinados por el carisma de un maestro, para aquiescer con entusiasmo con la devoción incondicional del militante, que siempre tiene algo de la fe del carbonero» (Passeron, 2003: 79).
\end{abstract}

Uno de los efectos tardíos de Mayo del 68 en el campo intelectual francés fue la conversión del trabajo social en un problema intelectual, respecto al

* Este trabajo se apoya (además de en la lectura de la producción bibliográfica relevante) en el análisis de las siguientes revistas de trabajo social publicadas en Francia entre el año 1968 y 1980: Informations sociales, Revue Française de Service Social, Revue Française des Affaires Sociales, La Vie Sociale y Champ Social. Se han realizado entrevistas con Robert Castel, Jacques Donzelot, Vincent de Gaulejac, Jeannine Verdès-Leroux, Michel Chauvière, Jean-Michel Courtois y Jean-Yves Barreyre. Este trabajo fue presentado en el congreso «Mai 68, creuset pour les sciences de l'homme?», celebrado en París del 10-12 de setiembre de 2008 organizado por la Société française pour l' histoire des sciences de l'homme.

Mis agradecimientos a Rodrigo Castro, Jean-François Gaspar, Gérard Mauger, Javier Ugarte y Francisco Vázquez por sus comentarios a diferentes versiones de este texto.

EMPIRIA. Revista de Metodología de Ciencias Sociales. N.o 17, enero-junio, 2009, pp. 141-163. ISSN: 1139-5737 
cual se dirimieron algunos debates importantes. En este texto me propongo describir cómo un dominio subordinado del saber, pudo convertirse en centro de una polémica intelectual que, a su manera, ayuda a comprender la cristalización de dos referencias centrales en la vida intelectual francesa: la representada por Bourdieu y por Foucault. El asunto, aunque circunscrito a un contexto histórico, me parece relevante para pensar las condiciones de posibilidad de los discursos cultos - por ejemplo, los de la filosofía o la teoría social- Como explicó con mucha fuerza Bourdieu utilizando un motivo del Parménides (130d) de Platón ${ }^{1}$, existe una jerarquía entre los objetos intelectuales que selecciona desigualmente las vocaciones: las más ambiciosas, se dirigen hacia los objetos nobles, las menos pretenciosas hacia los innobles. La novedad de la coyuntura que describo fue la de que un objeto claramente degradado en la jerarquía intelectual, el trabajo social, mereció la atención de una parte importante de la vanguardia de las ciencias humanas y sociales. De este modo, el círculo vicioso que confirma las jerarquías intelectuales se cortocircuitó y los objetos innobles dejaron de recibir el tratamiento de los menos ambiciosos que, suelen ser, mal que le pese a cualquier populismo, en muchos casos, los peor dotados intelectualmente. La reconstrucción en términos de campo intelectual permitirá comprender dicho acontecimiento sin el recurso al genio o al azar. Permitirá también derivar algunas lecciones sobre los procesos de creación intelectual novedosa y, en el caso español, comprobar cuanto separa la recepción canónica de la filosofía francesa de vanguardia de las razones por las que ésta fue, efectivamente, vanguardia de hecho y no proclamada.

\section{VANGUARDIA INTELECTUAL Y PROFESIONAL}

Antes de los años 70, hacía falta poca competencia específica para hablar del trabajo social. La cultura, entre los trabajadores sociales, servía como alibi con el que justificar un trabajo de moralización de su clientela difícil de enmascarar técnicamente ${ }^{2}$. El recurso a los representantes de los saberes «nobles», tal y como muestra el estudio de Verdès-Leroux (1978: 68-82) sobre los congresos de la Association Nationale des Assistants de Service Social (ANAS), servía como simple pretexto para legitimar la posición de los profesionales. Las intervenciones de los intelectuales en los congresos decía poco sobre la práctica del trabajo social y sus problemas. Los intelectuales — normalmente ligados a los poderes

\footnotetext{
1 Parménides pregunta a Sócrates si existen formas separadas de las cosas que «podrían parecer ridículas, tales como pelo, barro y basura». Sócrates lo niega y Parménides responde con una magistral lección de sociología de la filosofía —y de los discursos «importantes»—: «Claro que aún eres joven, Sócrates y todavía no te ha atrapado la filosofía, tal como lo hará más adelante, según creo yo, cuando ya no desprecies ninguna de estas cosas. Ahora, en razón de tu juventud, aún prestas demasiada atención a las opiniones de los hombres» (Platón, 1998: 43-44).

2 Sobre la transmisión pedagógica sin el amparo de una institución educativa véase el análisis en Bourdieu y Passeron (1979: 79-80).
}

EMPIRIA. Revista de Metodología de Ciencias Sociales. N.o 17, enero-junio, 2009, pp. 141-163. ISSN: $1139-5737$ 
políticos e institucionales del mundo universitario- concedían a los profesionales un crédito de neutralidad y rigor; los profesionales ofrecían a los intelectuales un mercado entregado y poco exigente que aumentaba el prestigio social del orador.

Después de mayo del 68, ya en los años 70, los profesionales del trabajo social reclaman nuevas formas de discurso teórico. Las palabras de ánimo y los discursos humanistas dejan de ser suficientes. Se exige un mayor rigor teórico; en respuesta a dicha demanda, un grupo importante de aspirantes a intelectuales producirá un nuevo tipo de discursos. Los receptores de los mismos en el mundo profesional, se singularizarán también, recogiendo y radicalizando tales diagnósticos, respecto de sus colegas menos innovadores.

Dicha coyuntura se muestra bien en el número 107 de La revue française du service social. Un artículo anunciaba un congreso en Versalles (1974) sobre «Le service social et la vie politique», señalando, a la vez, las razones por las que la vida profesional se había conmovido. Durante el congreso de Toulouse (1972), «un grupo de asistentes sociales pusieron en cuestión las bases mismas del servicio social». Posteriormente, en el congreso de Estrasburgo (1973), se exigió una «perspectiva sociológica» y «reflexiva y crítica» respecto del trabajo social ${ }^{3}$. El fin del congreso de Versalles era continuar con dicha dinámica de autoflagelación, eso sí, siempre según la visión de Jean-Pierre Worms (Centre de sociologie des organisations), vigilando «que las conclusiones no fueran demasiado duras y frustrantes». Descubrir las estructuras ideológicas de la práctica profesional, insistía el sociólogo, no debe estar reñido con la creencia en la creatividad ${ }^{4}$.

Había sectores profesionales, por el contrario, que vivían la situación de crisis como una oportunidad personal, profesional e intelectual. En buena medida, constituían un «frente interno» de revuelta que había jugado un papel de primer orden en el desencadenamiento de la crisis. Según una caracterización de dicha población (Muel-Dreyfus, 1983: 145-198), ésta compartía propiedades que la diferenciaban de los sectores más tradicionales: era una población más joven y masculina, tenía un origen social más diverso y utilizaba las zonas ambiguas del espacio social —esto es, las poco codificadas y fáciles de redefinir- para diferentes proyectos de reclasificación profesional. Además, se asiste a una expansión enorme del número de trabajadores sociales: en 1968 había 94.600 traba-

\footnotetext{
${ }^{3}$ Referencias a este congreso aparecen en La revue française du service social, 1973, 100. Se trataba de saber « Entre la demande sociale et les institutions, quelle est la place du service social ». Con la precaución de no transformar el congreso en «un congreso de sociólogos », se pidió a R. Sainsalieu, M. Mandelbaum y C. Blanquet del Centre de Sociologie des organisations de Michel Crozier, que introdujeran «Eléments de réflexion sur la fonction du social dans notre société présente ». El objetivo era clarificar «el significado político de la profesión». Michel Crozier era percibido como un sociólogo tecnócrata entre los sectores «críticos» del campo intelectual francés (Verdès-Leroux, 1978: 82).

${ }^{4}$ Según una reseña entusiasta del congreso, los sociólogos habrían satisfecho las esperanzas: «Realizaron una verdadera desmitificación de la política» y, por tanto, dejaron de atemorizar a su público con supuestas complicidades con el orden establecido.
}

EMPIRIA. Revista de Metodología de Ciencias Sociales. N. ${ }^{\text {17 }}$, enero-junio, 2009, pp. 141-163. ISSN: $1139-5737$ 
jadores sociales frente a 199.800 en 1975 (Monrose, 2000: 17). En tales condiciones, aparecía un público sensible a nuevos discursos de cuestionamiento de la identidad profesional: se reunían las condiciones sociales para una profecía (Bourdieu, 1992: 350).

En parte de esa población, dotada de una cierta conciencia de generación, el oficio de trabajador social, desmentía las esperanzas familiares de promoción social. Las condiciones para redefinir el puesto exigían separarse de una visión del oficio adscrita a una población femenina y conservadora. Por otra parte, la militancia política, nutrida e intensa en el post-68, proporcionó a muchos jóvenes profesionales del trabajo social un conjunto de «encuentros improbables» (en las situaciones normales...) con los representantes de la gran cultura filosófica parisina. Comienza una fuerte crítica del trabajo de normalización de las instituciones, en consonancia con las nuevas orientaciones de una parte de los intelectuales (Foucault, Deleuze...). Un GITS (Groupe d' information des travailleurs sociaux), según el modelo del GIP (Groupe d'information sur les prisons) ${ }^{5}$. En ese momento, el nombre de trabajo social se impone para referirse a prácticas muy diversas ${ }^{6}$. La denominación sirve para designar un entorno que se conoce mal y que se denuncia, demasiado masivamente, como escenario de prácticas de control social. (Autès, 1999: 50). Además, y es la otra cara de la moneda, permite referirse a un significante que un número de la revista Esprit, publicado en abril-mayo de 1972, va a convertir en dominio digno de reflexión intelectual.

\section{LA PRIMERA GENERACIÓN DE «FOUCAULTIANOS»: EL INTELECTUAL ESPECÍFICO, EL ASPIRANTE A TEÓRICO, EL MILITANTE}

El trabajo social —o el conjunto de profesiones que se unificarán con ese apelativo- era un lugar de inversión militante. Los acontecimientos de mayo del

\footnotetext{
5 Mayo de 1972, escribe Autès (1999: 49), fue una especie de mayo del 68 en el trabajo social. Diversos conflictos con las instituciones sacudieron la práctica profesional. En diciembre de 1971, Josette d'Escrivan, asistente social en la prisión de Fresnes, alerta sobre las malas condiciones de salud de un ciudadano americano detenido. D'Escrivan fue despedida. En una carta publicada por Esprit (D'Escrivan, 1972: 33-37) y dirigida a la ANAS, la asistente social apelaba a sus obligaciones profesionales para defender su labor. Diversos conflictos en centros de menores (en Nantes, en Caen, en la residencia de l'Espélidou) atraen la atención colectiva y estimulan el militantismo profesional (Autès, 1999: 51).

${ }^{6}$ Se incluyen en ellas desde cuadros medios (educadores especializados y jardín de infancia, asistentes sociales, animadores socioculturales) hasta trabajadores sociales familiares encuadrados dentro del personal de servicio. Tales profesiones tienen tareas diversas y gozan de un prestigio distinto: aquellas con obligaciones más concretas, reclutaban un personal de origen social más humilde y se dirigían a poblaciones fragilizadas de las clases populares. Las profesiones con tareas más «relacionales», tenían más sustento teórico, mayor prestigio simbólico y reclutaban agentes de origen social más variado (Verdès-Leroux, 1978: 142). Sobre la imposición de la acepción «trabajo social» a partir del número de Esprit véase Castel (1988a: 33).
}

EMPIRIA. Revista de Metodología de Ciencias Sociales. N.o 17, enero-junio, 2009, pp. 141-163. ISSN: 1139-5737 
68 lo habían conmovido. En este apartado presentaré tres perfiles que permiten comprender los rasgos de los diversos mundos que colaboraron en el acontecimiento que analizo. Por un lado, un agente que comenzará a teorizar sobre el trabajo social, por otro lado, alguien que utiliza el trabajo social para una proyección académica superior (porque decir que intelectualmente superior es un juicio de valor que no deseo hacer) y, en fin, un profesional que, constituyó una parte vertebral del proceso pero que no lo aprovechó para encontrar una proyección diferente.

\section{El trabajo social conecta trayectorias}

Michel Chauvière nació en Laval. Se diploma en psicopatología. «Después, cambié de perspectiva, bastante radicalmente, y me di cuenta que nunca sería clínico, que eso no me gustaba». Realiza estudios de sociología y lingüística en Rennes. Llega a París en 1970 porque «bueno, encontré un trabajo de formador en una escuela de educadores, gracias a un amigo que había estudiado psicología. En suma, por contactos. Pero no estaba muy metido en el trabajo social, no al $100 \%$. Por colegas, me pongo a dar algunos cursos en París VIII, en Vincennes. Estaba con un pie dentro y otro fuera de la Universidad. En el centro de formación, me ponen en contacto con la revista Esprit y Philippe Meyer [en la época próximo a Foucault y miembro también del Groupe d'information sur les prisons: $J L M P$ ]. Pero yo no era parisino, sino bastante provinciano. Como luego contó Bourdieu de sí mismo, yo tenía esa neurosis provinciana y de clase, desconfiada, protectora respecto de todos esos intelectuales parisinos. Porque Philippe Meyer y Jacques Donzelot estaban en ese medio como en su casa. El medio de los intelectuales parisinos de izquierda, críticos. Yo estaba en pleno desembarco, bastante sorprendido de lo que encontraba en París».

Entrevista con Michel Chauvière, París, febrero 2002

El testimonio Michel Chauviére, participante en el número de Esprit, resulta significativo de los conflictos existentes. Por una parte, Michel Chauvière (cuyo nombre aparece en las listas de las reuniones del mundo militante en trabajo social que pude consultar en los archivos de Jean-Michel Courtois, sobre el que hablaré en seguida) trabajaba en una institución inspirada en el personalismo de Emmanuel Mounier. Entonces, intentaba construir una «visión marxista del trabajo social» (Bessaguet, Chauvière, Ohayon, 1976: 30) que difícilmente cuadraba bien con el mundo del cristianismo personalista. Por otra parte, se encuentra acogido en la revista Esprit — al lado, entre otros, de Jacques Donzelot, Michel Foucault, Michel Meyer, Paul Virilio — para exponer su visión crítica del trabajo social. Leyendo el número, y salvo ciertos artículos, la coalición de críticos y católicos avanzados no sorprende tanto. Los artículos proponen pocos análisis concretos de la realidad profesional y tienen un aroma a crítica global de 
la civilización que, en aquel periodo, podía servir de punto de encuentro de católicos e izquierdistas. Objetivamente, Esprit actuaba con un gran sentido de la oportunidad: la ruptura con el catolicismo se encauzaba en discursos que, en su radicalismo, trascendían la crítica «vulgar» y hermanaban, de modo implícito, en la crítica del Partido comunista francés ${ }^{7}$.

Pero Esprit importa poco por su contenido teórico. Fue el lugar de consagración de, según Michel Chauvière, «la primera generación de foucaultianos». $\mathrm{Y}$ este encuentro entre la revista fundada por Mounier y Michel Foucault tendrá consecuencias en el espacio intelectual francés ${ }^{8}$. Jóvenes intelectuales inspirados por Foucault, aparecen con fuerza en el mundo intelectual. Según Michel Chauvière «Esprit ofrece un espacio para decir cualquier cosa, cosas que no se dirían en otros espacios. Empezaban a decirse, a hacerse y, bueno, eso tomaba formas un poco chapuceras. Están los trabajadores sociales que cuentan sus problemas; luego la gente como Michel Foucault y los demás que ven las cosas desde arriba, y desde arriba intentan problematizar la cuestión del trabajo social, pero sin enterarse de nada de lo que realmente pasa. Estaban los dos mundos. Las gentes que venían de arriba con todas las teorías sobre el control social y la gente de base. Pero la conjunción entre las dos lógicas no se realiza»?.

La evaluación realizada por Jacques Donzelot tiempo después confirma la descripción realizada por Michel Chauvière. Para él, el trabajo social constituía un espacio del conocimiento por debajo de sus primeras expectativas. Sobre el trabajo social, decía, «yo no conocía nada. Aún ahora, no conozco nada. El año 1972 estaba precedido por gente como Foucault, el GIP, mi miserable persona. Deleuze estaba también en el rollo. Había comenzado a trabajar un texto sobre el nacimiento de la prisión en 1969, a partir de Histoire de la folie. Foucault me quitó el problema. Y bien, muy bien. [...] Mi problema era un poco el de Foucault. Porque ¡yo no soy sociólogo! De formación soy historiador y filósofo $^{10}$. Comencé a enseñar sociología y me pareció extraño ese objeto ¿Para qué servía ese discurso? Porque hay un conjunto constituido por la sociología, por el trabajo social, todo eso forma un magma, un mismo conjunto. Lo cual me provocó distancia, y me dio ganas de teorizar. Teorizar es establecer los vínculos entre ese objeto y un problema al que responde. Es encontrar la pregunta a la que responde y encontrar la relación entre la pregunta y la respuesta. Más que jugar a ser el experto» ${ }^{11}$.

${ }^{7}$ Sobre los conflictos en la concepción del trabajo del Groupe d'information sur les prisons entre la fracción cristiana (procedente de Esprit y tendente al reformismo) y los jóvenes militantes alrededor de Foucault véase Defert (2003: 321).

${ }^{8}$ Por lo demás, la participación en Esprit suponía no participar en Les temps modernes, revista de Jean-Paul Sartre. Entre ambas revistas, los conflictos venían de largo (Boschetti, 1990: 154-158). Véase sobre esta cuestión Lindenberg (2001: 51-53).

9 Entrevista con Michel Chauvière, febrero 2002.

10 Según sus propias palabras, estudiaba Historia, pero estaba atraído por la filosofía de Foucault y seguía los cursos de Raymond Aron en la Sorbona (Donzelot, 2008: 48).

11 Entrevista con Jacques Donzelot, febrero 2002. 


\section{El trabajo social, lugar de vagabundeo de un «antisociólogo»}

Jacques Donzelot formó parte del departamento de sociología de la universidad experimental de Vincennes ${ }^{12}$, hoy París VIII, empresa en la que coincidirá con Foucault (por un breve tiempo: Foucault dejará pronto Vincennes para ir al Collège de France), Deleuze, Baudrillard, etc. Su tesis doctoral ( $L a$ police des familles) fue dirigida por Jean-Claude Passeron (Dosse, 2007: 370), quien a principios de los años 70, comenzaba a distanciarse de Pierre Bourdieu. Passeron, muy próximo personalmente de Foucault, describe el ambiente del izquierdismo militante y sus relaciones con la investigación sociológica, con esta anécdota: «Foucault, que me había acarreado con él en 1971 en uno de sus «golpes» políticos, el del GIP (Grupo de información sobre las prisiones) decidió que un análisis estadístico que había sacado de documentos cifrados sustraídos por sus amigos al Ministerio de justicia - y que, por lo demás, él consideraba interesante como medida de las oportunidades de encarcelamiento en función del status social de los delincuentes y del tipo de delitos- no habría sido buena propaganda para su línea de agitación intelectual de la opinión» (Moulin, Veyne, Passeron, 1996: 303). En un texto de homenaje a Robert Castel (filósofo de formación y, en la época, sociólogo próximo tanto de Foucault como de Bourdieu), Jacques Donzelot contaba sobre sí mismo: «Robert ha sido un poco mi iniciador en los dos dominios que nos importan aquí: el dominio universitario, ya que gracias a él me convertí en universitario en Vincennes en 1969 y, por otra parte, el de la producción escrita, porque fue quien me pidió mi primer artículo. [...] Fui el izquierdista de servicio de Robert, el que le molestaba llamándole «humanista quejica» (Bachmann, 1992: 12). Jacques Donzelot formó parte desde el comienzo (8 de febrero de 1971) del Groupe d'information sur les prisons animado por Michel Foucault (Artières, Quéro, Zancarini-Fournel, 2003: 30) En el número 12 de Esprit de 1972, Donzelot comentaba el Anti-Oedipe de Gilles Deleuze y Félix Guattari, citando Le psychanalisme de Robert Castel (que aún no había aparecido: lo hará en 1973) y la Critique de l'économie politique du signe de Jean Baudrillard. Su comentario

12 De allí pasó al departamento de sociología de Nanterre. Véase un relato fuertemente personal de Donzelot (2008). A Bourdieu le horrorizaba el ambiente de Vincennes, en el que Passeron se codeará también con Robert Castel. Aunque Passeron (2003: 115) encontraba justificada la crítica del movimiento de mayo a la fosilización universitaria, ha descrito con mucha viveza la podredumbre del movimiento parasitado por locos y por pillos, o por pillos que se hacían los locos de manera ruinmente oportunista: «En sociología, pero también en filosofía, matemáticas, informática, ciencias de la educación, etc., los viejos corrían a veces más rápido que los adolescentes más contestatarios para desbordar, en una sobrepuja liquidadora todo control de conocimientos y toda regularidad del trabajo intelectual; los jóvenes lobos quisieron rápidamente transformar en carrera universitaria garantizada de por vida, a ser posible al más alto nivel, su practica improvisada de la palabra de enseñante y su tendencia a reducir toda investigación a la exclusiva agitación contestataria y militante; allí se encontraban, claro está, izquierdistas inesperados, derechistas contrariados, de todas las edades y de todos los departamentos».

EMPIRIA. Revista de Metodología de Ciencias Sociales. N. ${ }^{\text {17 }}$, enero-junio, 2009, pp. 141-163. ISSN: 1139-5737 
muestra el mismo afán por guardar los privilegios del filósofo frente a las ciencias sociales, sin dejar, por lo demás de practicarlas. Para Donzelot, el libro de Deleuze y Guattari era una alternativa a la sociología, incapaz de liberarse del funcionalismo, de pensar las luchas marginales y de tratar en toda su complejidad el problema del Estado. El artículo contenía párrafos como el siguiente: «Por tanto, los procesos sociales no exigen ya una explicación en los términos de su lógica interna, sino en función de las inversiones con las que afectan las dos superficies que les rodean: la tierra y el Estado. Lo social ya no es un todo autónomo sino un campo de variaciones entre una instancia de agregación y una superficie de vagabundeo» (Donzelot, 1972: 849). Según Donzelot, Foucault, pese a lo que escribió publicamente, tenía poca estima por el Anti-Oedipe. Lo consideraba «un efecto de lenguaje, algo como Celine» (Dosse, 2007: 376). Castel, por su parte, celebraba el libro de Deleuze y Guattari, precisamente, por su capacidad para ensamblar el deseo con la experiencia social. Pero no dejaba de mostrar sus reservas respecto a la capacidad del texto para explicar la posición del psicoanálisis en la estructura social. En suma, Castel (1980: 242-247) valoraba lo que el libro tenía de sociológico y criticaba sus carencias al respecto.

Jean-Michel Courtois representa una experiencia diferente, solo parcialmente conciliable con la de Chauvière y Donzelot: buena parte del tono intelectual de este último, sólo se entiende comprendiendo las propiedades sociales que Courtois representa de modo casi cercano al tipo ideal. Por un lado, discursos como el de Donzelot trabajaron las actitudes culturales de personas como Courtois; por otro lado, supieron adaptarse a las mismas ${ }^{13}$. Courtois trabajaba como educador de calle y fue el fundador del Groupe d'information des travailleurs sociaux (GITS, que publicaba su manifiesto fundacional en el referido numero de la revista Esprit dedicado al trabajo social); en suma, el modelo de conjunción entre la práctica profesional y militante y la vocación de autodidacta. El contacto con el campo intelectual le permitirá realizar cursos en Vincennes —invitado por Jacques Donzelot - y convertirse en fundador de la revista Champ social, órgano del izquierdismo crítico en trabajo social. «Yo metía a la gente con la que trabajaba en la camioneta y las llevaba a escuchar a Michel Foucault. Todo lo que decía sobre las prisiones y el encierro. Era muy diferente de Bourdieu y nun-

13 Todo mensaje simbólico se adapta a un público — siempre con propiedades peculiares — al que le proporciona una determinada respuesta a sus específicas necesidades de sentido. Como decía Schumpeter - Imperialisme et classes sociales, París, Minuit, 1972, pp.77-82, citado por Passeron (2004: 38) — la Jihad hubiera sido distinta si se hubiese predicado a los pescadores y a los pobres de Galilea. No es difícil de imaginar que la prédica de la humildad por parte de Mahoma a los caballeros beduinos hubiera encontrado algunos problemas de recepción. Y que el mensaje hubiera debido transformarse o resignarse al fracaso. Sobre la adaptación mutua de demanda y producción de discurso entre teóricos y receptores de la teorías del control social véase Castel (1988b: 74).

EMPIRIA. Revista de Metodología de Ciencias Sociales. N.o 17, enero-junio, 2009, pp. 141-163. ISSN: $1139-5737$ 
ca fue un militante. Es un intelectual. Un filósofo. Nos dio muchas orientaciones sobre cómo concebir de modo diferente el trabajo social y también de cómo aplicarlo. Pero somos nosotros los que tenemos que partir de sus escritos (Histoire de la folie y Surveiller et punir, y quizás también L'archéologie du savoir) para saber qué sacar de nuestra propia tradición. Bourdieu, por el contrario, está más sobre el terreno» ${ }^{14}$.

\section{Un público perfecto para los grandes}

Jean-Michel Courtois nació en Poitiers, como uno de sus héroes intelectuales. Hijo de un peluquero convertido en director comercial de una gran empresa y de una empleada de la Banque de France. Estudia en el colegio Saint-Stanislas («un colegio que había frecuentado gente célebre como el Mariscal de Lattre de Tassigny y... Michel Foucault»). Aunque fue un lector muy precoz, tuvo una trayectoria académica muy conflictiva. Tras una trayectoria en el scoutismo, consigue un trabajo en un centro de observación de jóvenes delincuentes. Tras cuatro años de trabajo en los que consigue su diploma de educador, se marcha de Poitiers: «Cogí mi bastón de peregrino y subí a París. Fue el gran giro. Llegué en 1971. Era ya el post-68. Me fui en 1977 después de una ruptura familiar, política y profesional». Courtois era, en el momento de nuestra entrevista, todavía un creador de instituciones de trabajo social y un escritor activo. Durante la existencia de Champ Social, escribió muchos artículos en los que intentaba aplicar la «caja de herramientas» de Michel Foucault al trabajo social. Como muchos autodidactas, Courtois desprecia lo académico tanto como aprecia la verdadera «altura» intelectual: «Estoy sobre todo orgulloso de ser autodidacta. Me encanta cuando me encuentro un intelectual, un universitario y nos ponemos a hablar de cultura general y el tipo no se entera de nada. ¡Es una especie de goce! Pero, al mismo tiempo, siempre estuve atraído por los grandes intelectuales. ¡Siempre, siempre! Pero atraído si son intelectuales en el sentido griego del término. Pero con una condición: que sean grandes. A la vez que tengo esa admiración, porque no se puede decir de otro modo, es transferencia, procesos de identificación, si quieres, con gente como Foucault o Sartre, sólo tengo desprecio por todo lo que es escolar».

Entrevista con Jean-Michel Courtois, enero 2002

14 Passeron (2008) recuerda la mezcla de jóvenes marginales y de intelectuales — como Sartre, Foucault, Simone de Beauvoir, Jean Genet...- que componían las audiencias de grupos como el GIP.

EMPIRIA. Revista de Metodología de Ciencias Sociales. N. ${ }^{\text {17 }}$, enero-junio, 2009, pp. 141-163. ISSN: 1139-5737 


\section{OMNIPRESENCIA DEL PODER O REDEFINICIÓN DE LA DEMANDA}

Courtois, y los participantes en el GITS y la revista Champ social, fueron el público más receptivo a las inversiones intelectuales en el trabajo social. El discurso sobre las relaciones de poder - nuevo bien simbólico frente a un marxismo concebido como simplista- animó una especie de jdanovismo ${ }^{15}$ profesional: tras cada elección profesional, se veía una decisión política de primer orden; el trabajo social, por tanto, carecía de cualquier lógica propia y no era más que política enmascarada. El jdanovismo (con su máximo representante, el «biólogo» Trofim Lyssenko) recluta sus principales agentes entre quienes carecen de un alto capital específico dentro de un dominio determinado de la práctica científica o profesional pero, por el contrario, gozan de un enorme capital político. En el trabajo social, este «masoquismo profesional» se revistió de una idealización del usuario muy similar a las idealizaciones del proletariado de los ideólogos estalinistas. A la vez, como ya se ha comprobado, este jdanovismo se acompañaba, al menos en ciertos miembros de la vanguardia crítica, de una relación muy tradicional con la cultura - en el fondo, no tan lejana de la que caracterizaba al polo profesional más conservador, si seguimos los análisis de Verdès-Leroux (1978: 142, 164), con los que comenzaba este texto-. El desprecio a la cultura técnica —entre ella, la cultura difícilmente formalizable de una profesión con un fuerte componente clínico como el trabajo social- y la fascinación por la «alta cultura» (por la filosofía, los grandes intelectuales, el «estilo» literario) convierten a los autodidactas en reproductores ardientes de todos los tópicos de la «cultura noble» (Poliak, 1992: 35) ${ }^{16}$.

Sobre la recepción de este discurso en el mundo profesional, pueden utilizarse como indicador la reacción de ciertas revistas profesionales. Vie sociale, revista del CEDIAS-Musée Social ${ }^{17}$ consagraba una larga reseña al especial de Esprit en

15 Por Andrei Jdanov, ministro de cultura de Stalin y defensor de una epistemología y una concepción de la cultura reducida a sus efectos políticos. Ver la descripción de Passeron contenida en la nota 10 .

${ }^{16}$ Como ninguna persona responde a un modelo (salvo cuando media la pereza intelectual del analista), deben apuntarse dos cuestiones a propósito de Jean-Michel Courtois. Por un lado, no huyó de la vida profesional. Cuando lo visité en Saint-Etienne, me presentó con orgullo a su equipo de trabajo («eh, mirad, un tío que ha venido a entrevistarme. Explícales a estos por qué», me decía) y me mostró las instalaciones de su centro en un barrio extremadamente modesto. Por otro lado, su amor por la cultura no sucumbió a las decepciones de su vida: tampoco sus convicciones políticas, sobre las que discutimos hasta altas horas de la noche. Esta combinación entre profesionalismo activo y autodidactismo, entre amor por la cultura y fidelidad al «trabajo sucio», al trabajo concreto, seguramente, impidieron la reclasificación profesional y la movilidad social ascendente de Courtois, cuyo nombre seguía recordándose con respeto en París cuando realicé mis entrevistas. Sin duda, Courtois permanecía entonces como un dirigente virtual, si, alguna vez, una movilización de masas reaparecía. Para esta cuestión me inspiro en Mauger (1999: 123).

17 Fundación especializada en cuestiones sociales cuyo origen se remonta a la fundación del Musée social en 1894 por el Conde de Chambrun.

EMPIRIA. Revista de Metodología de Ciencias Sociales. N.o 17, enero-junio, 2009, pp. 141-163. ISSN: $1139-5737$ 
su número 8 de 1972. La revista aplaudía la originalidad, pero se lamentaba de «ciertos artículos sobrecargados de una jerga seudocientífica que da una impresión de hermetismo y de fatuidad capaz de desanimar al lector de buena voluntad», así como de la ausencia entre los autores de personas implicadas en la práctica cotidiana del trabajo social - lo que le servía, además, para alertar acerca de la escasa cultura teórica entre los profesionales-. Vie sociale constataba el éxito de Esprit entre los estudiantes, signo de la correspondencia entre la demanda y la oferta de discurso. La revista, por fin, se interrogaba sobre la procedencia de discursos teóricos ajenos a la vida profesional concreta. En suma, tras el ropaje modernista, se vislumbraba la vieja relación entre los discursos universitarios y el trabajo social. Las exigencias para hablar seguían siendo escasas.

La reacción de Informations sociales ${ }^{18}$ será más lenta. En 1972, la revista no hace ninguna referencia a Esprit y sus problemas permanecen circunscritos a problemáticas de política social. Habrá que esperar a 1973 para encontrar los ecos de las novedades teóricas. Un número especial sobre «Sciences humaines et travail social» ocupa los números 7 y 8 de ese año. El editorial propone una interesante lectura del conflicto. El problema estribaría en las resistencias conservadoras a la ciencia y a la existencia de «espíritus poco abiertos a la información». Esta evaluación tecnocrática, veneradora de la «verdadera ciencia, fuente de eficacia», «capaz de evaluar los límites de sus poderes», proponía así una traducción específica, distinta de la proporcionada por la Vie sociale, de la querella entre «antiguos»y «modernos». Un artículo de François Marquart propone recuperar el problema del poder, planteado por la nueva coyuntura, en términos susceptibles de resolución científica. La nueva Vulgata sobre la relación entre conocimiento y poder, se reformula en los términos, empíricamente más precisos, de la determinación de los objetos de investigación por la demanda social (sea del mercado, del Estado, etc.). Para esa tarea, Marquart se apoya en un conjunto sincrético de referentes teóricos. El artículo se abre con una foto de Pierre Bourdieu y, entre las referencias (junto, por ejemplo, al fundador de la sociología rural en Francia Henri Mendras), se encuentra el importantísimo artículo de Jean-Claude Chamboredon (1971: 335-357) sobre la delincuencia ${ }^{19}$.

\section{El capital cultural y la actitud revolucionaria}

Para comprender el público que recibe el mensaje de los «intelectuales críticos» vale la pena hacer una cala en algunas reacciones de profesionales publicadas en la revista Champ Social. Una lectora, que firmaba como «Asistente social desde 1946» (Champ social, $\mathrm{n}^{\mathrm{o}}$ 8, 1974, p. 4), esto es, una persona que

18 Revista de la Caisse nationale des allocations familiales. En la década de 1970, se convertirá en lugar de publicación de jóvenes intelectuales ligados al trabajo social.

19 Esta cultura sociológica sincrética — que agrupa sin problemas a Alain Touraine con Pierre Bourdieu — aparece también en el trabajo de André Nison (1975: 13, 37-38). 
se presentaba con todos los rasgos de la vieja generación situaba todo el discurso del control social en relación con ciertas realidades profesionales (prisión, hospitales, prevención de la delincuencia, psicólogos) especialmente difíciles: «Yo no entro en ese campo, decía la corresponsal, porque conozco otros donde se puede respirar». Pese a su contenido crítico, la carta confirmaba el capital cultural de los redactores: «Para terminar, algunas cuestiones sobre la FORMA. Aunque el vocabulario me disgusta a menudo, porque es demasiado vulgar, sin embargo, el francés es perfecto; encuentro importante decíroslo porque es muy raro en las publicaciones psicoreinvidicativas profesionales». Otra lectora, en el no 21 (1976), escribía: «Es una revista superintelectualizada. No tengo un diccionario suficientemente grande para leerla».

Si la selección de indicadores es correcta (aunque provisional y susceptible de ampliarse), puede determinarse los polos siguientes en el campo, en la época incipiente, de discursos sobre el trabajo social. Por una parte, el antiguo mundo profesional intentaba leer de modo técnico los problemas planteados por la vanguardia teórica y profesional. Este polo tenía un prestigio intelectual muy débil en un momento en que el capital político era una condición de reconocimiento intelectual, tras la conversión del «izquierdismo» en una idea fuerza del campo teórico. Por otra parte, un discurso elaborado por jóvenes intelectuales —o militantes que aspiraban a tal- especializados en rebuscar en las «cajas de herramientas» de los pensadores de prestigio (sobre todo, Michel Foucault). Por una parte, este discurso arrumbaba como antiguo el modelo de intelectual comprometido (representado por Sartre en el imaginario promovido por Foucault), sin dejarse de sentir distante de la capacidad de las ciencias sociales para profundizar en las relaciones de poder. Actualizando lugares comunes de la vieja cultura filosófica europea (Kusch, 1995), presentes en Francia con especial virulencia (Moreno Pestaña, 2006), tales ciencias eran consideradas, a la vez, ingenuas y peligrosas por una especie de pecado original. Ese discurso encontraba su público de predilección en una joven vanguardia de trabajadores sociales, dotados de una «cultura media ${ }^{20}$, que los volvía extraordinariamente sensibles - véase las consideraciones de Courtois - a los emblemas de altura intelectual —independientemente del rendimiento semántico de los mismos - ${ }^{21}$. Una «sociedad de admiración mutua» (Bourdieu, 1966: 872; 1992: 413; 1984: 229-230) se configuraba

${ }^{20}$ En el sentido en que utiliza Louis Pinto (1984: 21) el concepto. Se trata del tipo de capital cultural que se adquiere frecuentando las intersecciones entre distintos campos de la experiencia. Este tipo de capital cultural, que tiene sus cultivadores especializados - y hasta sus virtuosos-, es básico para la entrada y el mantenimiento en los ambientes más mundanos del espacio intelectual.

21 No hay ningún juicio peyorativo en esta afirmación, sino una recomendación de higiene hermenéutica, realizada por Bourdieu (1996: 16) y confirmada por mi experiencia indígena del mundo intelectual: «La hipótesis de que la gente se lee es muy arriesgada; y de que al leerse, se comprenden, es aún más arriesgada».

EMPIRIA. Revista de Metodología de Ciencias Sociales. N. ${ }^{\circ}$ 17, enero-junio, 2009, pp. 141-163. ISSN: 1139-5737 
en los «salones» militantes: el «filósofo comprometido en las luchas» era consagrado y a su vez consagraba a los «intelectuales específicos», que desvelaban el funcionamiento del poder, adaptando su realidad cotidiana a los esquemas del teórico. Según Jean-Yves Barreyre (en la época de nuestro encuentro director del CEDIAS, doctor en sociología — tesis con Michel Maffessoli- autor de múltiples obras sobre el trabajo social y segundo y último director de Champ Social) el intercambio simbólico, desde su punto de vista como trabajador social, se vivía de la manera siguiente: «La revolución permitirá a los profesionales hacerse un lugar; intentan teorizar para aportar un análisis sobre la sociedad. E intentan también, de manera completamente egocéntrica y egoísta, encontrarse un sitio en el campo de la acción y en el campo de los conceptos» ${ }^{22}$.

Este discurso militante perderá su capital simbólico con el cambio de humor político de los intelectuales y sus representantes en el mundo sectorial. Un ejemplo extraordinario, que vuelve innecesario extenderse, lo proporciona el comentario de Philippe Meyer (1977a: 3) a la presentación de la segunda edición del número de Esprit. Los radicales políticos, han vuelto protoliberales sus primores nietzscheanos (hasta hace poco ultraizquierdistas) ${ }^{23}$, y además de lamentarse del poco prestigio del trabajo social, se interrogan, siempre sorprendentes, sobre «la pesada herencia clerical, que envenena damas de la caridad e izquierdistas: la pasión de hacer el bien» ${ }^{24}$.

\section{¿Quién cita a quién?}

Un instrumento interesante para comprender hacia donde se orienta cada agente intelectual es objetivar su sensibilidad hacia los discursos teóricos. Una comparación entre cinco revistas de trabajo social entre 1970 y 1979 (año de la publicación del último número de la revista Champ Social) resulta instructiva al respecto. La Revue française du service social y la Revue française des affaires sociales no realizan referencia alguna a los debates intelectuales alrededor del trabajo social. Constituyen el polo más profesional de las revistas y el más lejano del campo de discursos de las ciencias humanas y la filosofía. Informations sociales y La vie sociale se hacen eco de los movimientos intelectuales y,

22 Entrevista con Jean-Yves Barreyre, enero 2002.

23 Jacques Donzelot considera que Philippe Meyer llevaba al extremo las visiones más caricaturescas de la ideología del trabajo social «control social». Entrevista con Jacques Donzelot, febrero 2002. La opinión de Donzelot se compadece bien con la lectura de los textos de Meyer (1977b).

${ }^{24}$ Las desinversiones en el trabajo social deben ser puestas en relación: con las modificación de las relaciones entre el campo político e intelectual (que sacuden Francia después de 1975), con la trayectoria de los agentes (proyectados, tras su rentabilidad sencilla en un campo acogedor, hacia dominios de mayor envergadura) y con las cegueras y los malentendidos específicos resultado de la convivencia en un espacio concreto de agentes que obedecen a lógicas diversas — por ejemplo, si mi perfil es correcto, Jean-Michel Courtois y Jacques Donzelot-.

EMPIRIA. Revista de Metodología de Ciencias Sociales. N.o 17, enero-junio, 2009, pp. 141-163. ISSN: 1139-5737 
muy significativamente, de los números de la revista Champ social: Informations sociales le dedica 6 referencias mientras que La vie sociale le dedica 5. Champ social en cuyo seno aparece toda la panoplia de productores intelectuales de prestigio (excepto Bourdieu aunque sí, en dos ocasiones, artículos contenidos en Actes de la recherche en sciences sociales referidos al trabajo social) no se refiere una sola vez a las revistas profesionales. La legitimidad de los malditos era enorme; su desprecio hacia todo lo que pareciese instalado, la consecuencia lógica.

El grueso del mundo profesional vivía la experiencia desde la mala conciencia y la sobreexigencia. Robert Castel recuerda ser invitado, junto a uno de los —entonces - jóvenes analistas del trabajo social, ante un público de profesionales que recibían una bronca enorme por parte del joven intelectual. «Yo estaba un poco molesto», explica Castel. «Creo que como no tienen teoría, estaban fascinados por la especulación intelectual. Tienen una tendencia a admirar la teoría. Ven a alguien como Foucault y se dicen que lo que éste cuenta debe ser verdad porque lo dicen grandes hombres. Pero se acabaron dando cuenta de que era injusto. En el trabajo social concreto las personas hacen lo que pueden. Lo que hacen no es siempre glorioso, pero en general son gentes de buena voluntad. No lo hacen por cuestión de pasta» ${ }^{25}$. Ese disgusto vital, se acompañaba en Robert Castel (1976: 5) con una crítica importante de los excesos izquierdistas en la crítica de los dispositivos de «saber-poder» y con la defensa de las condiciones racionales para el análisis intelectual. Lo decía claramente en la revista Champ social: «Quizá mi análisis no sea muy radical. Pero, si el psiquiatra es un «madero», ¿por qué hay psiquiatras $y$ «maderos»? El trabajo social está dividido de manera más fina y todas las prácticas no son idénticas. [...] Las condenaciones políticas de un cierto tipo no hacen más que moralizar el análisis».

Castel representaba, entonces y más tarde, otro polo en el debate. Dicho polo va aportando sus nombres propios procedentes de la nueva generación de jóvenes intelectuales. Aparece, primero, alrededor de una batalla sobre las «disciplinas» que deben introducirse en la formación de trabajadores sociales ${ }^{26}$. Un artículo, que tuvo un fuerte impacto, de René Barbier (1973), antiguo doctorando de Jean-Claude Passeron, reivindicaba la necesidad de la sociología para sacar al trabajo social de una dieta monótona de psicología. Varias son las características de este polo: primera, se expresa en un lenguaje «crítico» pero comprometido con el trabajo social real; segunda, ese lenguaje resulta asimilable por las revis-

25 Entrevista con Robert Castel, febrero 2002.

26 Según Vincent de Gaulejac que en la época realizaba también sus primeros pasos como sociólogo, la pelea disciplinaria se desarrollaba en los ámbitos teóricos pero también prácticos: se trataba, me explicó, de ver quiénes eran los supervisores de los equipos de intervención social. Entrevista con Vincent de Gaulejac, febrero 2002.

EMPIRIA. Revista de Metodología de Ciencias Sociales. N. ${ }^{\circ}$ 17, enero-junio, 2009, pp. 141-163. ISSN: 1139-5737 
tas especializadas y comprensible por sus lectores; tercera, la batalla contra el psicologismo (Barbier, 1974: 75) encontrará, entre muchos de los jóvenes intelectuales, un referente fundamental en la personalidad pública e intelectual de Robert Castel. Éste disponía de varias propiedades que lo preparaban para ese puesto: intelectual de talla, respetado por Foucault y por el campo sociológico, enemigo de los acercamientos arrogantes y despectivos respecto del trabajo social, teóricamente estable e ideológicamente previsible (algo que le faltará a Foucault y a muchos de sus discípulos, dados a los cambios, cuando no a las cabriolas teóricas y políticas), y, además, puerta institucional abordable y acogedora (habrá muchos tribunales de tesis de sociólogos procedentes del trabajo social en los que se sentará Robert Castel).

Pierres Lascoumes, analizando aquel periodo, escribía que sobre el trabajo social existían dos tipos de acercamientos teóricos: aquellos que lo idealizaban y aquellos que lo «situaban ${ }^{27}$. En aquella época, resultaba imposible no criticar el trabajo social si quería producirse un discurso de prestigio: fuera éste más o menos preciso, más o menos producto de tópicos, lo cierto, es que sin el cuestionamiento del trabajo social, no se podía entrar en el campo intelectual. Los grupos profesionales más antiguos estaban instalados en la conciencia de crisis desde hacía tiempo y dirigían a los sectores modernistas y tecnocráticos de las ciencias sociales una demanda de legitimidad. Pese a ello, no había consenso entre las nuevas generaciones acerca del valor de ciertos discursos críticos. Los discursos más radicales se juzgaban simplificadores y demasiado violentos respecto a los trabajadores sociales de base. Dichas reservas crecerán en tanto que el izquierdismo deje de ser un rasgo distintivo del mundo intelectual. Conforme la década de 1970 iba finalizando.

\section{SITUAR A LOS QUE SITÚAN}

Los principios de visión y división política comenzaban a perder su fuerza de imposición cuando apareció Actes de la recherche en sciences sociales. Hasta entonces Bourdieu era un intelectual poco conocido fuera de los círculos profesionales (Heinich, 2007: 9-12) y, según recuerda Jeannine Verdès-Leroux —con el tiempo convertida en una crítica furibunda-, fuertemente implicado en los trabajos de sus discípulos ${ }^{28}$. En los textos sociológicos sobre el trabajo social no era citado como representante de corriente o escuela sino agrupado con referencias críticas diversas: Alain Touraine, Gilles Deleuze y Félix Guattari, Michel Foucault, Philippe Meyer, Jacques Donzelot ${ }^{29}$.

${ }^{27}$ P. Lascoumes, «Le travail social idéalisé, situé, contesté», Déviance et société, no 3 . Citado por Pierre Grelley (1979: 5).

28 Entrevista con Jeannine Verdès-Leroux, enero 2005.

29 Véase por ejemplo el libro colectivo coordinado por J.-P. Liégeois (1977: 19, 22, 113, 119, 190-195). Se usa de él la noción de «arbitrario cultural» (en el artículo de J.-P. Liégéois

EMPIRIA. Revista de Metodología de Ciencias Sociales. N.o 17, enero-junio, 2009, pp. 141-163. ISSN: 1139-5737 
El prefacio del libro de Verdès-Leroux, inspirado por Bourdieu y publicado en la colección Le sens común de Éditions du Minuit, planteaba la discusión en dos terrenos. Constataba, en primer lugar, apuntando claramente con el lenguaje empleado cuál era el objetivo de su crítica, que el trabajo social proporcionaba un «status distinguido desde que algunos pueden integrarlo en una red de dispositivos de los que escrutan sus agenciamientos». Frente a ese modelo, Verdès-Leroux reafirmaba el poder de los agentes concretos, de su posición social y de sus recursos específicos: estos no se dejaban reducir a simples engranajes de grandes maquinarias que navegaban por encima del espacio y el tiempo. De ese modo, Verdès-Leroux presentaba el libro de Jacques Donzelot La police des familles como una variante del «proceso sin sujeto ${ }^{30}$ althusseriano combinada con una idealización de la marginalidad tópicamente contracultural. Pero, en segundo lugar, la crítica iba mucho más allá de lo epistemológico ${ }^{31}$. Será Bourdieu mismo quien la formule y en un artículo dedicado a uno de sus temas, el campesinado, con los que más estaba implicado personalmente ${ }^{32}$ - lo que creo que no es casual para comprender que en él eligiera al «izquierdismo» intelectual como objetivo, ni que se condujese en la discusión con tamaña acrimonia-.

Con un tono que recuerda el que utilizará contra Etienne Balibar o Bruno Latour, Bourdieu (2001: 378-396 y 2001b: 55-67) consideraba los trabajos críticos -refiriéndose a Anne Querrien, socióloga próxima de Guattari y Deleuze y a Jacques Donzelot - como una «ofrenda a los gustos del día en historia de las ideas y en especial al que se da aires de radicalismo atacando a adversarios que están muertos y enterrados» (Bourdieu, 2002: 251). Detrás de esos aires de radicalismo, Bourdieu sólo veía arrogancia de clase. Los tópicos ultraizquierdistas acerca de «los bloqueos libidinales de los maestros», los interpretaba como «una lección de savoir-vivre burgués a los maestros pequeñoburgueses y a sus sueños de poder». Como si la autocrítica estuviera al alcance del cualquiera, in-

«Autopsie du travail social de prévention » 0 « Travail social et classes sociales » de Bernard de Lock y Jean Grané) o en un uso spinozista de la noción de ideología (M. Autés «L'idéologie du travail social»). Temas que no servían entonces para definir una posición intelectual adscrita a una corriente.

${ }^{30}$ Con esta crítica, se atacaba la seña de identidad de un discurso que se quería una superación del marxismo en general y de Althusser en particular.

${ }^{31}$ En el libro de Verdès-Leroux (1978: 188) el lector encuentra una parte consagrada al fin del derecho liberal en beneficio de una acción normalizadora discrecional. Foucault había tratado esta cuestión en múltiples momentos de su obra. La referencia de Verdès-Leroux es... el libro de Ernst Cassirer, La philosophie des lumières.

${ }^{32}$ Se trata del artículo «Une classe objet», Actes de la recherche en sciences sociales, $\mathrm{n}^{\circ}$ 17-18, 1977. Cito según la edición que aparece en Bourdieu (2002). Sobre los trabajos sobre el campesinado y los orígenes sociales de Bourdieu véase Moreno Pestaña (2004). Robert Castel (2004: 313) recuerda que «alrededor de 1968, [Bourdieu] era extremadamente crítico respecto de las posiciones de radicalidad que representaban los distintos grupos «izquierdistas» de los que denunciaba, al menos en privado, el ethos de clase, en particular, su manera de hablar en nombre de la clase obrera, fundada sobre la ignorancia si no sobre el desprecio de lo que son los medios populares y sus aspiraciones».

EMPIRIA. Revista de Metodología de Ciencias Sociales. N.o 17, enero-junio, 2009, pp. 141-163. ISSN: 1139-5737 
sistía Bourdieu, y como si el análisis pudiera fundarse en el desprecio. Sólo una moral altanera, tan elitista como anticientífica, podía permitírselo: se percibía «indiferencia a las formas específicas que reviste la explotación entre las diferentes categorías de explotados y muy especialmente entre los pequeñoburgueses cuya alienación específica reside en el hecho de que a menudo, coaccionados y consintiendo, se hacen cómplices de la explotación de otros y de sí mismos». Y en una nota pie de página, fulminaba, de un modo que no deja lugar a dudas: «La intención misma de captar las razones de ser, además de que lo impide el desprecio de clase, supone una cosa distinta que la consulta de algunos textos pintorescos encontrados al azar en los archivos de la Biblioteca Nacional» (Bourdieu, 2002: 252).

La pereza científica tenía un enorme significado político. Estas obras eran un modelo culto de lo que en La distinción consideraba conexión entre la cultura del izquierdismo y los nuevos modos de organización de la dominación (Bourdieu, 1991: 370). Existía una convergencia entre los antiguos izquierdistas - que caminaban ya hacia nuevas coordenadas intelectuales - y las fracciones modernistas de la burguesía. Refiriéndose a Jacques Donzelot, escribía: «Denunciando, como lo hace otro, la manera fuerte en la época de la manera dulce, la dama de caridad que leía al barón de Gerando en la edad de la asistente social que cita su Lacan $^{33}$, esta historia liberada (del trabajo de investigación histórica) contribuye a legitimar el estado último de las instituciones de dominación que deben la mayor parte de su eficacia al hecho de que resultan profundamente desconocidas entre otras razones, porque se definen contra la retaguardia antigua-» (Bourdieu, 2002: 252-253).

Aunque más adelante Bourdieu prodigará los homenajes a Foucault, su juicio sobre las producciones que reclamaban su inspiración no podía ser más severo. La police des familles era «una historia hecha por encima que reunía todas las condiciones de un alto rendimiento simbólico sobre el mercado de los productos culturales: el va y viene incesante entre las alusiones cómplices al presente - capaces de producir el efecto de la gran crítica-y las referencias deshilvanadas y descontextualizadas al pasado - bien hechas para dar las apariencias de la «gran cultura»—y el cruce de exigencias que, como resultado, dispensan a la vez de toda investigación sistemática sobre el presente - lo que quitaría al discurso su altura filosófica- y de toda investigación profunda sobre el pasado —que reemplazando las instituciones y las prácticas en el sistema del que reciben su necesidad sociológica, constituiría el pasado como pasado y anularía el objeto de indignación retrospectiva» (Bourdieu, 2002: 153). Curiosamente, años después, Bourdieu utilizaba un sistema de categorías similar, pero cargándolas de un sentido positivo, para referirse a Michel Foucault, diciendo de él que «trabajó hasta el final para satisfacer las exigencias de la investigación histórica más avanzada. Gran trabajador y hombre de biblioteca

33 Véase Verdès-Leroux (1978: 51).

EMPIRIA. Revista de Metodología de Ciencias Sociales. N. ${ }^{\circ}$ 17, enero-junio, 2009, pp. 141-163. ISSN: 1139-5737 
combatió toda su vida para ampliar la definición, es decir la tarea y la misión de la filosofía. Lo que suponía mucho trabajo, para acumular las exigencias de dos tradiciones, la de la historia y la de la filosofía, en lugar de servirse de unas para escapar de las otras y recíprocamente - como se hace a menudo hoy e incluso a veces en su nombre— (Bourdieu, 2002b: 472) ${ }^{34}$.

Foucault, por su parte, incluía ciertas críticas a la obra de Bourdieu en su curso del Collègue de France de 1978-197935. En una parte del manuscrito de la lección del 14 de marzo, realiza una comparación entre la sociología de Bourdieu y la visión neoliberal del capital humano. La evaluación de Foucault (2004: 238) no resulta demasiado clara, pero confronta la teoría neoliberal del capital humano - que trata al individuo como una empresa - a la antropología de Bourdieu - fundada en una teoría compleja de las diversas formas de capital y sus posibles conversiones- ${ }^{36}$. Foucault encuentra la visión neoliberal del sujeto libre de todo supuesto antropológico y de toda noción de naturaleza humana. Lo que la hace menos normalizadora: lo que importa es lo que los sujetos hacen y no la naturaleza que se revela detrás de los mismos; naturaleza que permitiría la entrada de todas las empresas psicológicas de normalización (Foucault, 2004: 258-259). La asunción de una actitud pragmática ante el crimen le parece a Foucault sacar al neoliberalismo de las empresas disciplinarias ${ }^{37}$. Pero desarrollar

34 Véase P. Bourdieu, «Instituer efficacement l'attitude critique», D. Eribon, L'infréquentable Foucault. Renouveaux de la pensée critique, Paris, EPEL, 2001. Cito según el texto contenido en P. Bourdieu (2002b: 472). Esta diferencia de evaluaciones debe analizarse desde dos parámetros: uno, la evolución de las relaciones entre Bourdieu y Foucault dentro del campo intelectual francés; dos, la pluralidad de personajes que cada intelectual representa. Cada uno de esos personajes se muestra en una escena específica y, según la coyuntura, puede dejarse en hibernación, activarse en una o varias escenas o hipertrofiarse y ocuparlas todas. En mi entrevista con Robert Castel (febrero 2002), éste diferenciaba la actitud de Foucault — que entraba solo en parte en la crítica radicalcon la de Guattari — «un verdadero espíritu de desestructuración, que solo estaba feliz cuando se liaba el jaleo»- . Esta diferencia entre el que actúa con reservas mentales y es capaz de representar diversos personajes y el que se mueve por convicciones, nos ayuda a considerar los diversos tipos antropológicos que pueblan la vida intelectual y a mirar críticamente las evaluaciones intelectuales sin tener que recurrir a las simplificaciones del juicio moral. Sobre la cuestión del maquiavelismo y la convicción véase Passeron (1995: 69-70).

35 En un contexto, según Jacques Donzelot (2005) en el que se producía una fuerte viraje político de Foucault que lo acercaba a posiciones progresivamente moderadas. Ese giro es perceptible ya en un artículo firmado por el propio Jacques Donzelot. En él, por un lado, afirma la especificidad del análisis de Foucault contra su anexión marxista (Donzelot, 1978: 576), por otro lado, lo separa de la filosofía «aroniana» de André Glucksmann en Les Maîtres penseurs (el artículo era un comentario de este libro y de Patrick Virelet y Pierre Rosanvallon, Pour une nouvelle culture politique).

36 Según Daniel Defert, comentando la visión de Bourdieu por parte de Foucault, las relaciones entre contemporáneos se rigen por la no lectura mutua. Entrevista con Daniel Defert, diciembre 2004. Eso vale para la caracterización de Bourdieu por parte de Foucault —evidentemente fundada en la incomprensión - y también a la inversa: cuando Bourdieu se refiere al pensamiento de Foucault demuestra que lo conoce mal y muy simplificadamente. Véase por ejemplo Bourdieu (1989: 35).

37 Según Jacques Donzelot (Álvarez Uría, Donzelot, 2006: 53), Foucault se dirigía en la época a los miembros del partido socialista recomendándoles que inventasen una «gobernabilidad de iz-

EMPIRIA. Revista de Metodología de Ciencias Sociales. N.o 17, enero-junio, 2009, pp. 141-163. ISSN: $1139-5737$ 
este giro del pensamiento, difícil de captar teórica y políticamente, de Foucault requiere un espacio que desborda este texto. Aunque sin las cuestiones desarrolladas en él resulta difícil de comprender.

\section{CONCLUSIÓN}

La entrada de Bourdieu en el debate sobre el trabajo social — denunciando el discurso ligado a Foucault como una mezcla de oportunismo político y falsa apariencia intelectual - contribuye a tensionar el debate intelectual y, por tanto, a elevarlo. Las revistas profesionales lo perciben rápidamente ${ }^{38}$. Aunque los relatos grandilocuentes y no circunstanciados sobre el trabajo social (los dispositivos de control, la perfidia normalizadora, etc.) encontrarán curso intelectual, lo tendrán exclusivamente entre la enorme masa de importadores acríticos de la teoría francesa fuera del hexágono. Dentro de éste, hablar de trabajo social tendrá un coste cada vez mayor; por ello, cada vez recibirá la atención de mejores vocaciones intelectuales. Un objeto despreciado adquirió en una década un gran prestigio. Fue, sin duda, un tardío efecto teórico del Mayo francés que se conoce poco. Aunque en él se manifiesta con toda su profundidad una antigua reflexión de sociología del conocimiento con la que Parménides reconvino al joven Sócrates.

Sobre esa lección aun queda mucho por aprender. Los dos protagonistas que da la sensación que se enfrentaron (a través de personas interpuestas...) a propósito del trabajo social guardan en su economía teórica el efecto de esta coyuntura. Los textos de Foucault son excepcionales porque en ellos un filósofo — diferencia mínima pero enorme en una época que identifica filosofía con hermenéutica, sea de cuño heideggeriano o analítico- produce sus propios datos empíricos y teoriza sobre ellos: no se dedica a comentarios novedosos de los grandes del pensamiento ${ }^{39}$ o a reflexionar sobre uno o dos casos recogidos pretenciosamente de la

quierdas» que rompiese con el keynesianismo y con la administración pública de las necesidades. Según Donzelot, la imposibilidad de romper con el «trasfondo comunista» impide una política de izquierdas del individuo emprendedor similar a la neoliberal. Las derivas políticas diferentes de una corriente que cristalizó en esa época - y que unía a Foucault y Castel— se enfrentan en esta significativa conversación.

38 Por ejemplo, las reseñas casi entusiastas del libro de Verdès-Leroux en Vie sociale (nº 7 , 1978) que contrastan con el tono escéptico empleado para hablar de La police des familles en la misma revista $\left(n^{\circ} 4,1978\right)$. También las reseñas de los artículos de Verdès-Leroux aparecidos en la revista de Bourdieu Actes de la recherche en science sociale (Vie sociale $\mathrm{n}^{\mathrm{o}} 12,1975, \mathrm{n}^{\mathrm{0}}$ 7, 1976) o de Rémi Lenoir sobre la tercera edad aparecidos también en Actes (Vie sociale no 7, 1979). En un debate recogido en la revista Champ social Vincent de Gaulejac recoge el punto de vista de de Verdès-Leroux para discutir con un Jacques Donzelot que se encontraba ya de vuelta de todo izquierdismo (Donzelot y Gaulejac, 1978: 27-28).

39 Cualquier lector de Foucault sabe qué poca simpatía sentía ante las continuas demandas de los entrevistadores por situarse respecto a doctrinas o autores. Algo que, como recuerda Passeron (2003. 79), se lo exigían — a él y a Bourdieu — «interpelaciones que se referían siempre a autores

EMPIRIA. Revista de Metodología de Ciencias Sociales. N. ${ }^{\text {17 }}$, enero-junio, 2009, pp. 141-163. ISSN: $1139-5737$ 
realidad y levantando sobre ellos una lección de virtuosismo teórico. Los análisis de Bourdieu impresionan porque comprometen sobre temas cotidianos — seleccionados con una muestra razonada (o, al menos, mucho más cuidada que las típicas reflexiones, comunes entre los filósofos o los teóricos de altura, inspiradas en un acontecimiento arbitrariamente escogido) - una cantidad enorme de cualidades intelectuales que se demuestran útiles en tanto que aplicadas. Si el destino que la comunidad académica reserva a tales acontecimientos teóricos es introducirlos en la red escolástica del comentario filosófico (o de teoría social) existen razones para decir que la innovación que representaron se encuentra soslayada por el habitus escolástico. Y por sus fijaciones que son difíciles de conmover porque proceden más de obstinaciones de la voluntad que de confusiones de la inteligencia.

\section{BIBLIOGRAFIA}

Álvarez Uría, F. y J. Donzelot (2006): «Solos en la ciudad», Minerva, nº 2.

Artières, P., L. Quéro, y M. Zancarini-Fournel (2003): Le Groupe d'information sur les prisons. . Archives d' une lutte, París, IMEC.

Autès, M. (1990): Les paradoxes du travail social, París, Dunod.

Barbier, R. (1973): «Une analyse institutionnelle du travail social», Sociologie du travail, $\mathrm{n}^{\mathrm{o}} 1$.

- (1974): «Sociologie et travail social», Informations sociales, $\mathrm{n}^{\mathrm{o}} 7$.

Bessaguet, A.-M., M. Chauvière, A. Ohayon (1976): Les socio-clercs. Bienfaisance ou travail social, Paris, Maspero.

Blanchot, M. (1988): Michel Foucault tal y como yo lo imagino, Valencia, Pre-textos.

Boschetti, A. (1990): Sartre y «Les temps modernes», Buenos Aires, Nueva Visión.

Bourdieu, P. (1966): «Champ intellectuel et projet créateur», Les temps modernes, ํㅡㄴ 246.

- (1975): «Méthode scientifique et hiérarchie sociale des objets», Actes de la recherche en sciences sociales, $\mathrm{n}^{\mathrm{o}} 1$.

- (1984): Homo academicus, París, Minuit.

- (1989): «Reproduction interdite. La dimension symbolique de la domination économique», Études rurales, no 113-114.

- (1991): La distinción. Criterio y bases sociales del gusto, Madrid, Taurus.

- (1992): Les règles de l'art. Genèse et structure du champ littéraire, París, Seuil.

- (1996): «Qu'est-ce que faire parler un auteur? A propos de Michel Foucault», Sociétés et Représentations, 3, noviembre.

- (2001): Langage et pouvoir symbolique, París, Seuil.

- (2001b): Science de la science et réflexivité, Paris, Raisons d'agir.

- (2002): Le bal des célibataires. Crise de la société paysanne en Béarn, París, Seuil.

o doctrinas susceptibles de «clasificarnos» sobre una escala de compromisos de partido o de escuela según la manera en la que nosotros los clasificásemos a ellos». Esa actitud de discusión, profundamente enraizada en los procesos de socialización, formales e informales, en las facultades de filosofía o sociología hace que hoy Foucault o Bourdieu entren en la noria de comentados por comentarios que comentan, sobre todo, a los comentadores. Mucho más que a los supuestos referentes de los discursos. 
- (2002b): Interventions 1961-2001. Science sociale et action politique, Marseille, Agone.

Bourdieu, P. y J.-C. Passeron (1970): La reproduction. Eléments d' une théorie du système d'enseignement, París, Minuit.

Castel, R. (1976): «Champ social a rencontré Robert Castel», Champ social, no 21, junio.

- (1980): El psicoanalismo. El orden psicoanalítico y el poder, México, Siglo XXI.

— (1988a): «Du travail social à la gestion sociale du no travail», Esprit, no ${ }^{-}$-4.

- (1988b): «De l'intégration sociale à l'éclatement du social: l'émergence, l'apogée et le départ à la retraite du contrôle social», Revue internationale d'action communautaire, $\mathrm{n}^{\mathrm{o}} 80 / 60$.

- (2004): «Entre la contrainte sociale et le volontarisme politique», J. Bouveresse, D. Rocher, La liberté par la connaissance. Pierre Bourdieu (1930-2002), París Odile Jacob.

Chamboredon, J.-C. (1971): «La délinquance juvénile, essai de construction d'objet», Revue française de sociologie, XII.

D’Escrivan, J. (1972): «Peut-on ne pas dénoncer l'inacceptable?», Esprit, abril-mayo.

Defert, D. (2003): «L'emergence d'un nouveau front: les prisons», Artières, P., L. Quéro, y M. Zancarini-Fournel (2003): Le Groupe d' information sur les prisons. Archives d'une lutte, París, IMEC.

Donzelot, J. (1972): «Une antisociologie», Esprit, no 12, diciembre 1972.

- (1978) : «Misère de la culture politique», Critique, 1978, no 34.

Donzelot, J. y C. Gordon (2005) : «A propos de la gouvernementalité », http://www.donzelot.org/articles/Aproposdelagouvernementalit\%E9revuJrevuC_corr ection_colin_05.pdf

- (2008). «Devenir sociologue en 1968. Petite topographie physique et morale de la sociologie en ce temps-là », Esprit, no 344 .

Donzelot, V. y V. de Gaulejac (1978): «Où va le travail social ?» Champ Social, no 25.

Dosse, F. (2007) : Gilles Deleuze et Félix Guattari. Biographie croisée, París, La Découverte.

Foucault, M. (2004): Naissance de la biopolitique. Cours au Collègue de France. 19781979, París, Gallimard-Seuil.

Grelley, P. (1979): «Écrits accusateurs», Informations sociales, no 4-5.

Heinich, N. (2007): Pourquoi Bourdieu, París, Le Débat-Gallimard.

Kusch, M. (1995): Psychologism. A Case study in the sociology of philosophical knowledge, Londres, Routledge.

Liégeois, J.-P. (coord.) (1977): Idéologie et pratique du travail social de prévention, Toulouse, Privat.

Lindenberg, D. (2001) : «Michel Foucault et la revue Esprit: une relation complexe», La revue des revues, $\mathrm{n}^{\mathrm{0}} 30$.

Marquart, F. (1973): «La recherche peut-elle être sociale?», Informations sociales, no 7.

Mauger, G. (1999): «La volonté de savoir d'une documentaliste autodidacte et d'un ouvrier philosophe», in G. Mauger, C.F Poliak et B. Pudal, Histoires de lecteurs, París.

Meyer, P. (1977a): «Pourquoi le travail social?» Esprit, nº 4-5 (segunda edición).

- (1977b): L'enfant et la raison d'Etat, París, Seuil.

Monrose, M. (2000): «Une lecture statistique de l'histoire des travailleurs sociaux», J.-N. Chopart, Les mutations du travail social. Dynamiques d' un champ professionnel, $\mathrm{Pa}-$ rís, Dunod.

EMPIRIA. Revista de Metodología de Ciencias Sociales. N.o 17, enero-junio, 2009, pp. 141-163. ISSN: $1139-5737$ 
Moreno Pestaña, J. L. (2004): «Cuerpo, género y clase en Pierre Bourdieu», L. E. Alonso, E. Martín Criado, J. L. Moreno Pestaña (eds.), Pierre Bourdieu, las herramientas del sociólogo, Madrid, Fundamentos.

- (2006): Convirtiéndose en Foucault. Sociogénesis de un filósofo, Barcelona, Montesinos.

Moulin, R., P. Veyne, J.-C. Passeron (1996): «Un itinéraire de sociologue», Revue Européenne des sciences sociales, $\mathrm{n}^{-} 103$.

Nison, A. (1975): Travail social et méthodes d'enquête sociologique, Paris, ESF.

Passeron, J.-C. (1995): «Weber et Pareto: la rencontre de la rationalité dans l'analyse sociologique», L.-A. Gérard Varet, J.-C. Passeron (1995): Le modèle et l' enquête. Les usages du principe de rationalité dans les sciences sociales, París, EHESS.

— (2003): «Mort d'un ami, disparition d'un penseur», Revue européenne des sciences sociales, XLI.

- (2004): «Le sociologue en politique et vice versa: enquêtes sociologiques et réformes pédagogiques dans les années 1960», J. Bouveresse, D. Rocher, La liberté par la connaissance. Pierre Bourdieu (1930-2002), París Odile Jacob.

- (2008): Itinéraire d'un sociologue: trame, bifurcations, rencontres, París, La Découverte (en prensa).

Pinto, L. (1984): L'intelligence en action: le Nouvel Observateur, Paris, Métaillié Platón (1998): Diálogos V. Parménides, Teeteto, Sofista, Político, Madrid, Gredos. Poliak, C.-F. (1992): La vocation d'autodidacte, París, L'Harmattan.

Verdès-Leroux, J. (1978): Le travail social, Paris, Minuit.

\section{RESUMEN}

Este trabajo reconstruye los efectos de Mayo del 68 en el trabajo social en Francia. Su objetivo es realizar un estudio de caso acerca de la relación de los intelectuales con los entornos políticos y con los ámbitos profesionales. Para ello, y apoyándose en un trabajo sobre archivos (que incluye todas las publicaciones de trabajo social en la época) y en entrevistas (con algunos de los profesionales y de los intelectuales más destacados), se reconstruye el contexto profesional, posteriormente el intelectual $\mathrm{y}$, finalmente, las trayectorias de algunos de los principales agentes. El artículo concluye mostrando los efectos paradójicos del acontecimiento en la reflexión intelectual sobre el trabajo social. Por un lado, sirvió para cristalizar un conflicto acerca del tipo de «intelectual crítico» en Francia. Por otro lado, permitió la conversión del trabajo social (disciplina poco legítima) en lugar de inversión de energías intelectuales.

\section{PALABRAS CLAVE}

Historia y teoría de la sociología, sociología crítica, servicios de bienestar social, sociología de los intelectuales, movimientos sociales, interacciones políticas.

EMPIRIA. Revista de Metodología de Ciencias Sociales. N.o 17, enero-junio, 2009, pp. 141-163. ISSN: 1139-5737 


\begin{abstract}
This task rebuilds the results in social work in France on May '68. The point is to make a study about relation among intellectuals in political environments and professional environments For that, and being supported in a filing searching (that includes all publications of social work of the age) and in interviews with the mos outstanding professionals and intellectuals, the professional context is reconstructed, then the intellectual context and finally trajectories of the main agents.

This issue concludes demonstrating the paradoxical effects of such happening in the intellectual reflections on social work. In one side it was useful to clear up a problem about the intellectual critics in France. By other hand, it allowed social work (not at all legitimate discipline) to become in a place of intellectual energies investment.
\end{abstract}

\title{
KEYWORDS
}

History and theory of sociology, radical sociology, welfare services sociology of intellectuals, mass phenomena, political interactions 